\title{
lodine deficiency: socio-economic problems and new approaches to its solution in veterinary medicine
}

\author{
Alexey Yevglevsky ${ }^{1}$, and Andrey Gostev ${ }^{1}$ \\ ${ }^{1}$ Kursk Federal Agricultural Research Center, 70b, K. Marx st., 305021, Kursk, Russia
}

\begin{abstract}
One of the global, vital problems of humanity is iodine deficiency. According to the World Health Organization (WHO), more than 2 billion people live in conditions of iodine deficiency. people: among them, 740 million have endemic goiter, 43 million have mental retardation, more than 6 million. they suffer from cretinism (an extreme degree of mental retardation). Currently, iodine deficiency diseases are the most common non-infectious diseases in the world.

What about mammalian animals? In animals, iodine performs the same functions as in humans. Animals, especially agricultural animals, are just as sensitive to iodine deficiency as humans. With a lack of iodine in the body of animals, the biosynthesis of thyroid hormones is disrupted, which leads to a decrease in the intensity of redox processes, as a result of which all types of metabolism are disrupted:-protein, fat, carbohydrate, macro - and microelement, energy. In this regard, the failure of the thyroid gland is accompanied by the development of severe pathobiochemical processes, which, in the end, leads to the clinical manifestation of pathophysiological conditions. Taking into account the fact that in conditions of constant iodine deficiency it is very problematic to ensure the health of productive animals, the issues of prevention of iodine deficiency conditions are economically significant for industrial animal husbandry. It is no accident that in countries experiencing natural iodine deficiency, state programs have been developed that provide for the use of iodine-containing additives in the diets of productive animals. Despite the fact that the simplest and most affordable method of eliminating iodine deficiency in humans and animals is the inclusion of iodized salt in the diet, however, this method can not be used for veterinary purposes. First of all, the feed method of using biologically active additives eliminates the possibility of dosed therapeutic or preventive treatment. On the pages of this article, we draw attention to the emerging prospects for the use of a new iodine-metabolic composition in non-infectious and infectious pathology, based on an iodine polymer complex known in pharmacology as iodinol and succinic acid.
\end{abstract}

\section{Introduction}

One of the global, vital problems of humanity is iodine deficiency. According to the World Health Organization (WHO), more than 2 billion people live in conditions of iodine deficiency. human. 740 million people on the planet have endemic goiter, 43 million have mental retardation, and more than 6 million have it. they suffer from cretinism $[1,2]$.

And what about Russia? Russia is a country in which there are practically no regions with a sufficient content of iodine in water and soil. It is quite obvious that the inhabitants of the country do not receive the necessary amount of this vital trace element with food. According to the results of epidemiological studies, $75 \%$ of Russian residents experience varying degrees of severe iodine deficiency [3]. Due to iodine deficiency in Russia, every year more than 1 million children are born with the threat of intellectual development disorders, about 350 thousand of them, about 130 thousand are physically weakened, with irreversible changes in the development of the Central Nervous System, a decrease in mental development, 650 thousand children (every fifth child) have a goiter [3,4,5]. The direct consequences of iodine deficiency are dwarfism, extreme degree, up to cretinism, mental retardation, deafness, strabismus. These pathologies are laid in the prenatal period. It is at the early stages of intrauterine development under the influence of thyroid hormones that the development of the nervous, cardiovascular system, and musculoskeletal system occurs. As for the aged category of people, due to iodine deficiency, every year in Russia more than 1.5 million adults seek medical help with various thyroid diseases. More than 50 million (one of three) suffer from various diseases $[3,4,5]$. By themselves, these data indicate the social significance of iodine deficiency and the threat to the intellectual potential of the country's population. Recent studies have shown that individuals born in conditions of iodine deficiency have an intellectual development coefficient (IQ) 10-15 points lower than that of their age peers from iodine-rich areas [5].

According to epidemiological studies of the Endocrinological Research Center of the Russian Academy of Medical Sciences (1991-2000), it was found that iodine deficiency is most pronounced in rural areas and low-income groups in cities [3,4]. Due to the lack of propaganda, the population of the country knows 
little about the consequences of iodine deficiency. In this regard, the average consumption of iodine per inhabitant of the country is $40-80$ micrograms per day, which is 3 times less than the WHO recommended norm. Aggravating the situation is a sharp rise in prices for seafood rich in iodine. In fact, seafood, with the exception of seaweed, has become inaccessible to the bulk of the country's population. At the same time, financially affordable seaweed is practically not included in the diet.

Iodine deficiency in the body leads to the formation of conditions not only with obvious clinical signs. In one degree or another, almost every adult feels the symptoms of iodine deficiency. Symptoms of iodine deficiency can be-a constant feeling of fatigue, drowsiness, apathy.

This is how a significant decrease in thyroid hormones, which are responsible for the vital energy of the body, manifests itself [4]. A person with a low level of thyroid hormones experiences a constant feeling of hunger. Hence, people suffering from hypothyroidism are overweight. The problem of excess weight in people is global. With iodine deficiency, anemic syndrome develops. This is also a global problem. Anemic syndrome is registered in every fourth inhabitant of the planet. In the age group of people, the level of cholesterol increases (atherosclerosis), memory suffers $[3,4,5]$. This is also the fate of almost every elderly person. Thus, the spectrum of pathophysiological conditions caused by iodine deficiency includes almost all vital aspects of human health.

However, the manifestation of pathophysiological conditions is the visible signs of iodine deficiency. The problem is much deeper. It is no accident that the WHO designated it as SoS.

Thus, with iodine deficiency, it is impossible to protect the body not only from pathogens of acute infections. Against the background of iodine deficiency, even the most powerful antibiotics are not effective against ubiquitous infectious agents. It is no accident that WHO experts believe that overcoming the iodine deficiency will be as much a victory for public health as the elimination of smallpox and poliomyelitis. Assessing the threat of iodine deficiency to the physical, social and intellectual state of the world's population, International health organizations such as WHO, the International Committee for the Control of IodineDeficient Diseases, the United Nations Children's Fund, and others have developed a whole package of documents aimed at developing and implementing national programs to eliminate iodine deficiency and diseases associated with it. It should be noted that this has brought some positive changes in the geography of iodine deficiency diseases. Thus, in 14 European countries (Austria, Germany, Sweden, Switzerland, the United Kingdom, Norway, Iceland, the Czech Republic, Finland, the Netherlands, Bulgaria, Croatia, Macedonia, Slovakia), the indicators of the WHO recommended level of iodine consumption were achieved. In three other countries - Poland, Serbia, and Greece-the problem of iodine deficiency is close to being resolved. Iodine deficiency still persists in countries such as
France, Denmark, Belgium, Italy, Luxembourg, Portugal, Spain, Bosnia, Hungary, Ireland, Portugal, Romania, Slovenia, Turkey, and Russia [3].

As for veterinary medicine, despite the widespread iodine deficiency, the problem of iodine deficiency did not go beyond the scope of scientific research [6,7]. And here's why. Managers of livestock farms, veterinary specialists and animal breeders, as a rule, associate violations of the growth and development of young animals, high sensitivity of the body to infectious agents, metabolic disorders, reduced productivity and reproductive ability of animals with various adverse factors, but not with iodine deficiency. And in vain. The fact is that in the body of animals, iodine performs the same functions as in the human body. Animals, especially productive ones, are just as sensitive to iodine deficiency as humans. With a lack of iodine in the body of animals, the biosynthesis of thyroid hormones is disrupted, which leads to a decrease in the intensity of redox processes, as a result of which all types of metabolism are disrupted:-protein, fat, carbohydrate, macro - and microelement, energy. In this regard, the failure of the thyroid gland is inevitably accompanied by the development of severe pathobiochemical processes, which, in the end, leads to the clinical manifestation of pathophysiological conditions .

Another aspect is related to the fact that against the background of iodine deficiency, the use of certain medications, vitamin preparations, metabolites, vaccines will not have a pronounced positive result. In this respect, the most significant are the problems with vaccination of animals. In response to the introduction of vaccines, there are cases of low antibody production or even their loss, post-vaccination complications and clinical diseases [8]. Now this is especially evident when conducting epidemiological measures against coronavirus infection. Taking into account the fact that in conditions of constant iodine deficiency it is very problematic to ensure the health of productive animals, the issues of prevention of iodine deficiency conditions have become economically significant for industrial animal husbandry [9]. It is no coincidence that in countries experiencing natural iodine deficiency, state programs have been developed that provide for the use of iodine-containing additives in the diets of animals [10-13].

Despite the fact that the simplest and most affordable method of eliminating iodine deficiency in humans and animals is the inclusion of iodized salt in the diet, however, this method can not be used for veterinary purposes. First of all, the feed method of using biologically active additives eliminates the possibility of dosed therapeutic or preventive treatment. As for the iodized salt, it is necessary to take into account the fact that the concentration of iodine in it is unstable and during storage is significantly reduced, up to complete loss. In this regard, the use of iodized salt separately when added to feed or as part of premixes can not be considered an effective approach. A more rational approach to the prevention of diseases associated with iodine deficiency, including ensuring optimal regulation of metabolic processes in the body, may be the use of 
chelated compounds. Currently, chelated complexes of trace elements are widely used in medicine, animal husbandry, and crop production. And this is quite justified. In such compounds, the bioavailability of trace elements increases several times. Nevertheless, the biological activity of the chelate complex depends on the correct choice of a particular ligand. This circumstance was also taken into account when determining the author's search studies in the development of a complex iodometabolic drug suitable for the injection method of administration [14]. It is quite obvious that the injectable method of administration of iodine-containing drugs makes it possible to carry out therapeutic or preventive treatment in a dosed manner. By the way, this aspect has not yet found practical implementation in humane medicine. On the pages of this article, we present a theoretical justification for obtaining a new iodine-metabolic composition based on an iodine polymer complex known in pharmacology as iodinol and succinic acid and evaluating the effectiveness of its use in clinically expressed iodine deficiency.

As a justification for obtaining an energy metabolic composition, we consider it appropriate to present the following arguments. The preparation Iodinol is an aqueous solution consisting of iodine $(0.1 \%)$, potassium iodide $(0.9 \%)$, polyvinyl alcohol [15]. Iodinol, in contrast to elemental iodine, is low-toxic, has antiviral, antimicrobial and antifungal activity [16]. Since 1960, when the drug iodinol was officially registered by the Pharmaceutical Committee of the USSR, a huge clinical experience in the use of iodinol in medicine and veterinary medicine has been accumulated. Many people are still surprised by the truly unique therapeutic effectiveness of the use of iodinol in infectious and noninfectious pathology. However, up to the present time, the drug iodinol has been used externally and enterally (per os). Taking into account that iodinol does not irritate the mucous membranes, this determines the possibility of its injectable use. It should be noted that the author of the drug iodinol V. O. Mokhnach was the first to admit the possibility of using yodinol not only enterally or externally, but also subcutaneously, intramuscularly, intravenously [16]. This laid the foundation for expanding the scope of clinical use of the drug iodinol.

In turn, the unique spectrum of the metabolic action of succinic acid (SA) predetermined the possibility of its use as a metabolic component. And here's why. SA is a powerful stimulator of the metabolism of a living cell. The object of SA action is cells and tissues that are in a state of excitation or pathologically altered $[17,18]$. The stimulating effect of succinic acid is particularly pronounced in the weakening of the body and its disease $[18,19]$. The absolute harmlessness of UC and its salts (succinates), its ability to have an exceptionally high positive effect, even at very low dosages $(10 \mathrm{mg} / \mathrm{kg})$, make it a very valuable component in the development of a new generation of "smart" drugs, food and feed additives [20,21,22].

Currently, it is a universal component that is widely used to improve the pharmacological activity of drugs
[21].

Working in this direction for many years, we have accumulated extensive experience in its use for the qualitative improvement of a number of well-known drugs in veterinary medicine that have side effects or contraindications [22]. In our studies, it was found that the inclusion of succinic acid in the composition of iodinol in the amount of $1 \%$ or sodium succinate with a similar concentration of succinic acid, allowed to qualitatively improve its pharmacological properties [9, 14]. This allowed us to identify new approaches to the use of this composition in infectious and non-infectious pathology. In this work we focus the attention of researchers on the energy-metabolic qualities of the iodine-energy-metabolic composition in the injection method of administration.

\section{Material and methodology of clinical experiments}

The subjects for testing were calves and cows with clinically pronounced signs of iodine deficiency. Laboratory diagnostics of iodine deficiency conditions was performed based on the results of the determination of thyroid hormones in the blood serum - Thyroxine and Triiodothyronine by enzyme immunoassay on an automatic Teacan Sunrise analyzer.

\section{Research results and discussion}

Clinical experiment in calves. The initial clinical status is a lag in growth and development, a violation of the growth of the hairline, its peculiar curly and disheveled appearance, alopecia on the head and body, dermatitis, with a predominant localization in the distal extremities. All these clinical forms of lesions are most characteristic of hypomicroelementosis, iodine and vitamin deficiency. The results of biochemical studies of the blood serum of calves with clinical lesions were also confirmed. These calves had extremely low background indicators of reserve alkalinity-12-13 nmol/1 (metabolic acidosis), glucose levels-1.2-1.4 (energy deficiency), hemoglobin-73-76 g/l (anemic syndrome), copper, zinc, cobalt (hypomicroelementosis), traces of carotene (beriberi), protein-74-77 g/l (hypoproteinomy). The level of triiodothyronine (T-3) averaged $0.7-0.9 \mathrm{nmol} / 1$ in patients, versus 2.6-3.0 in healthy subjects; Thyroxine (T-4)-18-22 nmol/L in patients, versus $37-43 \mathrm{nmol} / \mathrm{L}$ in healthy subjects (iodine deficiency). These indicators indicate that with clinically pronounced iodine deficiency, calves develop a cascade of pathobiochemical processes that occur in the type of metabolic acidosis, anemic syndrome with a pronounced violation of energy metabolism.

The clinical experiment was conducted according to the classical design. In the calves of the first experimental group, the iodometabolic composition was tested, and in the animals of the second group, the pharmacopoeial iodinol was tested. The tested drugs were administered intramuscularly in a volume of $5 \mathrm{ml}$ (20,000 micrograms of iodine). This is a fairly high dose 
of iodine. Taking into account the rather severe clinical status of the calves and, in fact, the new method of injecting the drug iodinol, the number of experimental calves in each group was 5 individuals.

In the course of clinical observations, it was found that pronounced changes in the experimental calves of the first group were indicated after a day of using the iodine-metabolic composition. At first, this was manifested by improved appetite. On days 17 to 20, the calves of this group showed hair growth in areas with alopecia and improved hair cover. However, the clinical effect of reducing dermatic lesions was insufficient. The cause of the deficiency was a deficiency of trace elements of iron, copper, cobalt, and zinc. Actually, this aspect was the reason for the insufficient reduction of the anemic syndrome, in which the aerobic path of energy metabolism is difficult. However, judging by the glucose index, in the blood of calves on which the modified iodinol was tested, it actually reached the lower limit of physiological values. This effect is due to the fact that SA has a high ability to activate energy metabolism in conditions of hypoxia (anemic syndrome). The effect of normalization of the acid-base balance was positive and quite expected. The fact is that during the metabolic transformations of UC or its saltssuccinates, sodium hydroxide is formed. Here it is and deoxidizes the body. It should be noted that the normalization of the acid-base balance index, in this case it is an indicator of the reserve alkalinity, is a kind of indicator of the state of redox processes in the body of animals and humans. The use of pharmacopoeial iodinol in the calves of the second group did not have such a pronounced metabolic effect. In animals of this group, the glucose and reserve alkalinity values were lower than the physiological values (Table 1).

Table 1. The effect of the iodine-metabolic composition on the biochemical status of calves with clinically pronounced iodine deficiency

\begin{tabular}{|c|c|c|c|c|}
\hline $\begin{array}{c}\text { Indicator } \\
\mathrm{s}\end{array}$ & $\begin{array}{c}\text { Regulator } \\
\mathrm{y} \\
\text { indicators }\end{array}$ & $\begin{array}{c}\text { Backgroun } \\
\text { d data }\end{array}$ & $\begin{array}{c}\text { For the } \\
\text { 10th day }\end{array}$ & $\begin{array}{c}\text { For the } \\
\text { 20th day }\end{array}$ \\
\hline $\begin{array}{c}\text { Total } \\
\text { protein, } \\
\mathrm{g} / \mathrm{l}\end{array}$ & $72-86$ & $\begin{array}{c}62,3 \pm 2,1 \\
63,4 \pm 2,3\end{array}$ & $\begin{array}{c}69,3 \pm 2,5 \\
64,7 \pm 2,2\end{array}$ & $\begin{array}{c}71.3 \pm 2,6 \\
66,1 \pm 2,5\end{array}$ \\
\hline $\begin{array}{c}\text { Glucose, } \\
\text { mmol/1 }\end{array}$ & $2,2-3,3$ & $1,6 \pm 0,01$ & $2.1 \pm 0,01$ & $2,3 \pm 0.02$ \\
$1,6 \pm 0,01$ & $1,8 \pm 0,02$ & $1.9 \pm 0,01$ \\
\hline $\begin{array}{c}\text { Reserve } \\
\text { alkalinity } \\
\text { mmol/1 }\end{array}$ & $19-27$ & $12,65 \pm 0,56$ & $18,31 \pm 1,0$ & $\begin{array}{c}18,32 \pm 1,1 \\
2\end{array}$ \\
\hline T-3 & $2,6-3,0$ in & $0,72 \pm 0,31$ & $6,31 \pm 0,47$ & $8,32 \pm 0,51$ \\
healthy & $0,75 \pm 0,27$ & $5,26 \pm 0,32$ & $6,02 \pm 0,37$ \\
\hline T-4 & $37-43$ in & $11,3 \pm 0,74$ & $24,9 \pm 1,07$ & $36,8 \pm 1,05$ \\
& healthy & $11,6 \pm 0,89$ & $21,7 \pm 1,02$ & $29,2 \pm 1,04$ \\
\hline
\end{tabular}

Note: The upper line is the indicators for the calves of the first experimental group; the lower line I the indicators for the second experimental group.

The results of biochemical studies indicated the potential and the opening prospect of the injection method for using modified iodinol not only as an effective approach to the relief and elimination of symptoms of iodine deficiency, but also as an active energy-metabolic drug.
The following clinical experiment was conducted on cows with clinically pronounced signs of iodine deficiency with the presence of bangs on the head, mane, alopecia. Modified iodinol was tested on the cows of the first experimental group $(n=5)$, and pharmacopoeial iodinol on the animals of the second group $(n=5)$. The tested drugs were administered intramuscularly in a volume of $10 \mathrm{ml}$ (40,000 micrograms of iodine).

Table 2. Effect of iodine-polymer preparations on the biochemical status of cows

\begin{tabular}{|c|c|c|c|c|}
\hline \multirow[b]{2}{*}{ Indicators } & \multirow[b]{2}{*}{$\begin{array}{c}\text { Backgroun } \\
\text { d data ( } 30 \\
\text { days } \\
\text { before } \\
\text { calving) } \\
\end{array}$} & \multicolumn{3}{|c|}{ Research Days } \\
\hline & & $\begin{array}{c}2-3 \text { days } \\
\text { before } \\
\text { calving }\end{array}$ & $\begin{array}{c}\text { On the } \\
15 \text { th day } \\
\text { after } \\
\text { calving }\end{array}$ & $\begin{array}{c}\text { On the } \\
\text { 30th day } \\
\text { after } \\
\text { calving }\end{array}$ \\
\hline $\begin{array}{c}\text { Total } \\
\text { protein, } g / 1\end{array}$ & $\begin{array}{l}83,2 \pm 2,7 \\
82,8 \pm 3,5 \\
84,3 \pm 2,7\end{array}$ & $\begin{array}{l}\mathbf{8 1 , 3} \pm \mathbf{2 , 5} \\
82,3 \pm 2,7 \\
83,3 \pm 2,6\end{array}$ & $\begin{array}{l}\mathbf{8 1 . 4} \pm \mathbf{3 , 8} \\
85,6 \pm 2,7 \\
86,5 \pm 3,3\end{array}$ & $\begin{array}{l}\mathbf{8 1 , 5} \pm \mathbf{3 , 3} \\
87,1 \pm 2,8 \\
92,3 \pm 4,1\end{array}$ \\
\hline $\begin{array}{c}\text { Glucose, } \\
\mathrm{mmol} / 1\end{array}$ & $\begin{array}{l}2,1 \pm 0,03 \\
2,0 \pm 0,02 \\
2,1 \pm 0,03\end{array}$ & $\begin{array}{l}2.2 \pm 0,03 \\
1,9 \pm 0,02 \\
1,8 \pm 0,02\end{array}$ & $\begin{array}{l}\mathbf{2 , 5} \pm \mathbf{0 . 0 4} \\
2.2 \pm 0,03 \\
2.2 \pm 0,03\end{array}$ & $\begin{array}{c}\mathbf{2 , 7} \mathbf{\pm 0 , 0 5} \\
2,3 \pm 0,02 \\
1,9 \pm 0,02\end{array}$ \\
\hline $\begin{array}{c}\text { Reserve } \\
\text { alkalinity, } \\
\text { mmol/l }\end{array}$ & $19-27$ & $\begin{array}{c}18,94 \pm \\
1,98 \\
19,07 \pm \\
1,84 \\
19,14 \pm \\
1,79 \\
\end{array}$ & $\begin{array}{c}23,62 \pm \\
1,75 \\
18,51 \pm 1,2 \\
1 \\
16,12 \pm 0,9 \\
8 \\
\end{array}$ & $\begin{array}{l}25,43 \pm 1,19 \\
19,34 \pm 1,22 \\
15,17 \pm 1,01\end{array}$ \\
\hline $\begin{array}{l}\text { Triglyceride } \\
\mathrm{s}, \mathrm{mmol} / 1\end{array}$ & $\begin{array}{l}4,25 \pm 0,31 \\
3,98 \pm 0,27 \\
4,02 \pm 0,31\end{array}$ & $\begin{array}{c}4,02 \pm 0,2 \\
4 \\
4,26 \pm 0,3 \\
1 \\
4,45 \pm 0,3 \\
7\end{array}$ & $\begin{array}{c}\mathbf{3 , 9 6} \pm \mathbf{0 , 1} \\
\mathbf{4} \\
4,28 \pm 0,1 \\
7 \\
4,72 \pm 0,2 \\
3 \\
\end{array}$ & $\begin{array}{l}\mathbf{3 , 8 4} \pm \mathbf{0 , 1 7} \\
4,25 \pm 0,21 \\
4,75 \pm 0,19\end{array}$ \\
\hline $\begin{array}{c}\text { Cholesterol, } \\
\mathrm{mmol} / 1\end{array}$ & $\begin{array}{l}4,25 \pm 0.22 \\
4,31 \pm 0,15 \\
4,26 \pm 0.12\end{array}$ & $\begin{array}{c}\mathbf{3 , 8 6} \pm \mathbf{0 , 1} \\
\mathbf{4} \\
3,95 \pm 0.2 \\
2 \\
4,02 \pm 0.2 \\
7\end{array}$ & $\begin{array}{c}\mathbf{3 , 9 6} \pm \mathbf{0 , 1} \\
\mathbf{9} \\
4,28 \pm 0.2 \\
1 \\
5,35 \pm 0.2 \\
9\end{array}$ & $\begin{array}{l}\mathbf{3 , 8 9} \pm \mathbf{0 , 1 8} \\
4,85 \pm 0.19 \\
6,23 \pm 0.32\end{array}$ \\
\hline $\begin{array}{c}\text { Total } \\
\text { bilirubin, } \\
\text { mmol/1 }\end{array}$ & $\begin{array}{l}6,72 \pm 0,91 \\
7,04 \pm 0,85 \\
7,03 \pm 0,82\end{array}$ & $\begin{array}{c}8,31 \pm 0,7 \\
8 \\
8,69 \pm 0,9 \\
1 \\
8,02 \pm 7,6 \\
9\end{array}$ & $\begin{array}{c}8,37 \pm 0,7 \\
6 \\
9,04 \pm 0,6 \\
8 \\
9,78 \pm 1,0 \\
2 \\
\end{array}$ & $\begin{array}{c}\mathbf{8 , 3 9} \pm \mathbf{0 , 8 7} \\
9,75 \pm 1,03 \\
11,27 \pm 1,1 \\
9\end{array}$ \\
\hline $\begin{array}{l}\text { Ketone } \\
\text { bodies, } \\
\text { mmol /1 }\end{array}$ & $\begin{array}{l}0,4 \pm 0,01 \\
0,5 \pm 0,02 \\
0,5 \pm 0,02\end{array}$ & $\begin{array}{l}0,6 \pm 0,02 \\
0,8 \pm 0,03 \\
0,9 \pm 0,04\end{array}$ & $\begin{array}{c}0,7 \pm 0,02 \\
0,9 \pm 0,3 \\
1,3 \pm 0,04\end{array}$ & $\begin{array}{l}\mathbf{0 , 9} \pm \mathbf{0 , 0 3} \\
1,2 \pm 0,04 \\
3,1 \pm 0,07\end{array}$ \\
\hline $\begin{array}{l}\text { AlAT, } \\
\text { units/1 }\end{array}$ & $\begin{array}{l}47,4 \pm 3,2 \\
48,2 \pm 3,1 \\
49,3 \pm 3,1\end{array}$ & $\begin{array}{l}43,6 \pm 2,9 \\
45,8 \pm 3,0 \\
48,6 \pm 3,6\end{array}$ & $\begin{array}{l}\mathbf{4 1 , 7} \pm \mathbf{3 , 1} \\
56,3 \pm 3,1 \\
63,5 \pm 3,3\end{array}$ & $\begin{array}{l}\mathbf{4 3 , 3} \pm \mathbf{3 , 3} \\
54,5 \pm 3,4 \\
62,8 \pm 4,5\end{array}$ \\
\hline $\begin{array}{l}\text { AsAT, } \\
\text { units/l }\end{array}$ & $\begin{array}{l}89,5 \pm 3,7 \\
90,2 \pm 4,2 \\
90,4 \pm 4,1\end{array}$ & $\begin{array}{l}87,4 \pm 4,1 \\
91,4 \pm 4,3 \\
93,5 \pm 4,2\end{array}$ & $\begin{array}{l}90,3 \pm 4,6 \\
93,6 \pm 4,7 \\
98,2 \pm 4,5\end{array}$ & $\begin{array}{l}89,8 \pm 4,1 \\
95,7 \pm 4,5 \\
98,4 \pm 4,3\end{array}$ \\
\hline $\mathrm{T}-3 \mathrm{nmol} / \mathrm{l}$ & $\begin{array}{c}2,6-3,0 \text { in } \\
\text { healthy }\end{array}$ & $\begin{array}{c}2,31 \pm 0,4 \\
7 \\
2,36 \pm 0,4 \\
2 \\
2,26 \pm 0,2 \\
3\end{array}$ & $\begin{array}{c}4,37 \pm 0,5 \\
2 \\
3,25 \pm 0,2 \\
4 \\
1,34 \pm 0,3 \\
2\end{array}$ & $\begin{array}{l}8,32 \pm 0,51 \\
6,02 \pm 0,32 \\
1,02 \pm 0,37\end{array}$ \\
\hline $\mathrm{T}-4 \mathrm{nmol} / \mathrm{l}$ & $\begin{array}{l}37-43 \text { in } \\
\text { healthy }\end{array}$ & $\begin{array}{c}32,7 \pm 2,9 \\
8 \\
31,6 \pm 2,8 \\
7 \\
31,9 \pm 2,8 \\
9\end{array}$ & $\begin{array}{c}34,9 \pm 2,5 \\
7 \\
21,7 \pm 1,0 \\
2 \\
21,7 \pm 1,0 \\
2\end{array}$ & $\begin{array}{r}43,5 \pm 3,05 \\
29,4 \pm 1,95 \\
19,2 \pm 1,52\end{array}$ \\
\hline
\end{tabular}

Note: The upper line is the indicators of the cows of the first experimental group (iodinol in combination 
with SA); the middle line is the indicators of the second experimental group (pharmacopoeial iodinol); the lower line is the indicators of the cows of the control group.

The initial biochemical status of cows indicated that the indicators of total protein, triglycerides, total bilirubin, the main transamination enzymes aspartateaminotransferase (AsAT and alanine-aminotransferase (AlAT), were mainly above the upper limit of physiological values. The glucose level is within the lower limit. The level of reserve alkalinity is lower than physiological values (metabolic acidosis). The most pronounced changes in the biochemical status of experimental cows of the compared groups appeared on the 15 th day after calving. At the same time, in the cows of the first experimental group, on which iodinol was tested in combination with succinic acid, the indicators of protein and glucose content were within the average physiological values. This indicated that the energy processes of fat oxidation in the liver proceed without any deviations. Actually, this is evidenced by the low levels of ketone bodies. The use of pharmacopoeial iodinol in the cows of the second group did not have such a pronounced metabolic effect. In the animals of this group all biochemical parameters were either lower (glucose) or higher (total lipids, total bilirubin, cholesterol, ketone bodies, transamination enzymes ACAT and AlAT). During this period, by an order of magnitude more pronounced deviations from the physiological values were indicated in the cows of the control group. This is due to the activation of the involvement of the body's own lipids in the metabolism. This is indicated by an intensive increase in the formation of ketone bodies and a very high level of triglycerides.

On the 30rd day in the control group of cows, the indicators of total protein, lipids, bilirubin, and ketone bodies were $20-30 \%$ higher than the physiological values. Below the norm was the level of glucose (energy deficiency). The thyroid hormone levels were two to three times lower. On the contrary, in the cows of the first and second groups, which were injected with iodine-polymer preparations, the level of thyroid hormones was at the level of the background values of clinically healthy animals of the dry period. Another aspect is related to energy exchange. If we judge by the blood glucose index of the cows of the first group, on which the iodine metabolic composition was tested, then it was in fact higher than the average physiological values. Iodine, no matter how useful it is, does not have energy activity. It is able to stimulate the synthesis of thyroid hormones. But this activity has SA. In the body, only SA, and not other substrates of the Krebs cycle oxidation, monopolizes the respiratory chain. But this is a real approach to activating the aerobic, most productive pathway of energy production. The fact is that the aerobic pathway of energy synthesis is 18 times higher than the anaerobic pathway. This is many times stronger than infusions with glucose. It should be noted that back in the 1970s, in the research of Professor Kudryashova M. N. from the Institute of Biophysics of the USSR Academy of Sciences $[17,18]$, it was revealed that succinic acid has an exceptionally high ability to activate redox processes. The results of clinical experiments allow us to draw the following conclusion.

Conclusion. A technologically simple method for obtaining an energy-metabolic composition based on an iodine-polymer complex and a metabolic of succinic acid suitable for the injection method is theoretically justified.

According to the mechanism of action, the new iodine metabolic composition provides a pronounced activation of energy metabolism, which allows it to be attributed to a new class of iodine preparations-energy metabolics.

With the injection method of administration, in the generally accepted standard dosage, the iodine-energy metabolic composition provides: fast and effective elimination of symptoms of iodine deficiency; pronounced correction of pathobiochemical processes; activation of the involvement of the most problematic substrates such as lactate and ketoacids in the energy metabolism.

\section{References}

1. Assessment of iodine deficiency disorders and monitoring their elimination: a guide for programme managers, in WHO, United Nations Children's Fund, International Council for the Control of Iodine Deficiency Disorders, 3 ed., Geneva (2007)

2. Assessment of Iodine Deficiency Disorders and Monitoring their Elimination, in WHO, United Nations Children's Fund, International Council for the Control of Iodine Deficiency Disorders. 2nd ed., Geneva (2001)

3. N. M. Platonova, Clin. \& Exp. Thyroidology, 11, 1 (2015)

4. N. M. Platonova Iodine deficiency diseases (prevention, diagnosis, treatment and monitoring): Autoref. diss. D. Med. Sci., Moscow (2010)

5. I. I. Dedov, G. A. Melnichenko, E. A. Troshina, N. M. Platonova, F. M. Abdulkhabirov, L.N. Shatnyuk, B. P. Apanasenko, S. R. Kavtaradze, M. I. Arbuzova, F. A. Dzhatoeva, Iodine deficiency-a threat to the health and development of children in Russia. Ways to solve the problem, National report, Moscow (2006)

6. R.T. Mannapova, S. N. Aukhatova, Zh. Izvestiya Orenburg State Agrar. Univ., 4 (2004)

7. S.A. Manukalo, A. Kh. Shantyz, Vet. Med. Kuban, 5 (2014)

8. V.A. Mishchenko, A.V. Mishchenko, R.V. Yashin, G. V. Gladilin, Problems of animal vaccination:known and unknown, in Materials of the International scientific and practical conference "Problems and prospects of scientific and innovative support of the agro-industrial comple of regions", Kursk (2020)

9. A. A. Evglevskiy, V. N. Skira, G. F. Ryzhkova, I. I. 
Mikhailova, J. Bull. Ros. Agr. Sci., 2 (2019)

10. N. Bader, U. Möller, M. Leiterer, K. Franke, and G. Jahreis. Invest. in Jen, Thuringia. Submit. for publ. (2003).

11. L.B. Rasmussen, L. Ovesen, I. Bulou, T. Jorgensen, N. Knudsen, P. Laurberg, H. Perrild, Lone Brit. J. Nutr., 87 (2002)

12. E. N. Pearce, S. Pino, X. He, H. R. Bazrafshan, S. L. Lee, L. E. Braverman, (2004) J. Clin. Endocrinol. \& Metabol., 89(7) (2004)

13. G. Jahreis, M. Leather, K. France, W. Maichrowitz, F. Schone, V. Hesse, Kinderpraxis 16 (1999)

14.A. A. Yevglevsky, I. I. Mikhailova, V. N. Skira, E. P. Yevglevskaya, N. V. Vanina, O. N. Mikhailova, Vet. Pathol., 4 (2015)

15. I. E. Mozgov, Pharmacology, Moscow, Kolos (1979)

16. V. O. Mokhnach, A. V. Valdman, P. D. Evdokimov, Iodinol in medicine and veterinary medicin, Leningrad, Nauka (1967)

17. M .N. Kondrashova, Therapeutic effect of succinic acid, Pushchino, 4 (1976)

18. M. N. Kondrashova, The therapeutic effect of succinic acid/-Pushchin (1976)

19. Yu. Yu. Ivnitskii, A. I. Golovko, A. G. Safronov, Succinic acid in the system of means of metabolic correction of the functional state of organism resistance, St. Petersburg, Lan (1998)

20. E. I. Majewski, B. V. Grishina, A. S. Rosenfeld, Substantiation for the use of biologically active additives based on succinic acid, in Efficiency of use of dietary supplements in various fields of medicine: Materials of scientific-practical conference on biologically active additives, Moscow (2000)

21. A. L. Kovalenko, N. V. Belyakova, Pharmacy, 5-6 (2000)

22. A. F. Lebedev, O. M. Shvets, A. A. Evglevsky, E. P. Evglevskaya et al. Vet. Med., 3 (2009) 